\title{
NOTICIAS
}

\section{Informe del uso de la irradiación como medida de intervención en salud pública}

Durante la XI Reunión Interamericana de Salud Animal a Nivel Ministerial (RIMSA XI), que se llevó a cabo en la ciudad de Washington, D.C., Estados Unidos de América (EUA), del 13 al 15 de abril de 1999, se presentó el Informe 1993-1998 del Programa de Investigación Coordinada FAO/OIEA/OPS/OMS (Organización de Naciones Unidas para la Agricultura y la Alimentación, Organización Internacional de Energía Atómica, Organización Panamericana de la Salud y Organización Mundial de la Salud, respectivamente), cuyo propósito fue contribuir a la protección de alimentos con elevado riesgo de contaminación.

Debido a que se notificaban anualmente alrededor de $1.5 \mathrm{mi}$ llones de casos de enfermedades transmitidas por los alimentos, lo que constituía un problema mundial complejo para la salud pública y la productividad laboral, se reconoció que el éxito en la mejora de la salud pública mediante la protección de los alimentos dependía del despliegue de intensos esfuerzos de cooperación por parte de todos los países, sus instituciones gubernamentales, el sector privado y otras organizaciones interesadas en la inocuidad de los alimentos.

Como resultado de una consulta técnica conjunta de las organizaciones internacionales mencionadas, realizada en Washington, D.C., del 19 al 21 de octubre de 1992, se recomendó un plan de acción de cinco años que contemplaba la formulación de un programa de investigación coordinada que estableciera el marco para los estudios conjuntos, cuyo objetivo era demostrar la eficiencia y la eficacia de la irradiación en la protección de los alimentos. El plan de acción fue apoyado por la RIMSA VIII, celebrada también en Washington, D.C., en abril de 1993.

En el programa de investigación participaron 15 científicos de diversos países latinoamericanos y de EUA; siete participantes, de Brasil, Chile, Cuba, EUA, México, Perú y Uruguay concluyeron la investigación y presentaron sus resultados.

Irradiación para inactivar cisticercos de Taenia solium en la carne de cerdo

Los estudios anteriores habían revelado que para matar los metacéstodos de Taenia solium en el músculo porcino se requería de una dosis de radiación de hasta 7.0 kilograys (kGy). Los resultados del presente estudio indicaron que con $0.3 \mathrm{kGy}$ se puede evitar con éxito el desarrollo de la tenia adulta tras la ingestión de los cisticercos irradiados en el músculo porcino, aunque el metacéstodo mantiene un aspecto normal y todavía puede evaginar.

También se concluyó que deben continuar los estudios preliminares en los que se utiliza la fragmentación del ADN como medición de la pérdida de la infectividad en los metacéstodos irradiados de T. solium, ya que el método parece ser prometedor en aplicaciones futuras para estudiar los efectos de la radiación en otros parásitos. Esto puede incluir protozoarios de cultivo difícil o imposible, como Ciclospora cayetanensis, del cual no se conoce otro huésped que el ser humano. Además, se recomendó que la investigación futura en esta esfera incluyese la medición de la expresión de los genes celulares que inducen la muerte en los metacéstodos irradiados como índice del daño irreversible al parásito inducido por la irradiación.

Irradiación para la descontaminación de peces, moluscos y crustáceos

Se realizaron experimentos in vitro con el objeto de evaluar el efecto de la irradiación en diversos biotipos y serotipos de Vibrio cholerae grupo $\mathrm{O} 1$ y de una cepa perteneciente al grupo O139; V. parahaemolyticus, V. vulnificus y $V$. fluvialis. También se estudia- 
ron bacterias patógenas tales como: Aeromonas hydrophila, Plesiomonas shigelloides, Salmonella typhi, Salmonella enteritidis, Salmonella typhymurium, Shigella flexneri y Escherichia coli O157:H7.

Asimismo, se realizaron estudios in vivo usando ostras y mejillones que fueron inoculados con cultivos puros de $V$. cholerae y $S$. enteritidis mediante el mecanismo de alimentación natural de los moluscos. Las ostras y los mejillones se mantuvieron en tanques que contenían agua de mar inoculada con los microrganismos de interés. Las dosis de radiación aplicadas a las ostras se ubicaban dentro del rango de 0.5 - $3.0 \mathrm{kGy}$ en incrementos de $0.5 \mathrm{kGy}$.

El recuento de células viables en las ostras disminuyó en función de la dosis de radiación absorbida. El Vibrionaceae y otros cultivos sometidos a la prueba fueron considerablemente más sensibles a la radiación que la Salmonella spp. Se demostró que las dosis inferiores a $3.0 \mathrm{kGy}$ proporcionaban niveles de inocuidad razonables incluso contra S. enteritidis, suponiendo que el número de células viables potenciales es tan bajo como debería si se observan procedimientos primarios óptimos de producción y se aplica la metodología de análisis de peligros y puntos críticos de control.

Los experimentos con ostras y mejillones irradiados, no inoculados, indicaron que el proceso de irradiación a dosis de hasta $3.0 \mathrm{kGy}$ no es letal para las variedades de moluscos utilizados en el estudio, los cuales sobrevivieron hasta 10 días después de la intervención; lo anterior permitiría la comercialización de ostras frescas, aún vivas, como lo exigen los mercados de algunos países latinoamericanos.

Se estudió, asimismo, la eficacia del tratamiento con radiación ionizante para eliminar la contaminación potencial con $V$. cholerae biotipo $\mathrm{O} 1$
El Tor en diversas especies de peces autóctonas de la costa del Pacífico de América del Sur. Los pescados y mariscos estudiados incluían una especie de camarón (Penaeus vannamei), y los populares peces jurel (Trachurus picturatus murphyi) y lisa (Mugil cephalus). Los pescados y algunos otros productos examinados se consumen con frecuencia crudos, a veces como ceviche. Se llegó a la conclusión de que una dosis comprendida en el rango de 1.0 - $1.2 \mathrm{kGy}$ aseguraría la ausencia de $V$. cholerae en estos productos.

Se llevaron a cabo determinaciones paralelas de los posibles efectos adversos de la irradiación en características organolépticas seleccionadas de los productos. Se determinó la aceptabilidad de los moluscos, crustáceos y pescados crudos irradiados, objeto del estudio, durante un periodo de hasta 30 días a $0-1^{\circ} \mathrm{C}$, recurriendo a un panel no adiestrado. En general, la irradiación mejoró el aspecto de todos los productos, con excepción de la lisa, en comparación con los controles no irradiados; la aceptabilidad de todos los productos, excepto la lisa, se prolongó varios días, duplicándose para las almejas y los camarones con una dosis de radiación de 2.0 kGy. Se obtuvo un resultado similar en cuanto a las calificaciones del olor, el sabor y la textura. La lisa perdió aceptabilidad debido a cambios de color que se consideraron indeseables. Estos efectos dieron lugar a un aumento general del periodo máximo de almacenamiento de todos los productos estudiados, que se atribuyó a las disminuciones inducidas por la radiación de la microflora de descomposición de los productos.

Irradiación para la descontaminación de hortalizas frescas

Se inoculó artificialmente lechuga comercial fresca (Lactuca sativa) envasada en bolsas de polietileno, re- pollo (Brassica oleracea) y apio (Apium graveolens) envasado en una película de PVC retractable, con $V$. cholerae biotipo El Tor serotipo O1 Inaba a niveles comprendidos entre 10000 y 100000 células/g. Los productos se irradiaron 24 horas después de cosechados a 0.50, 0.70 y $1.0 \mathrm{kGy}$. Se utilizaron muestras no irradiadas como controles. Se midió el efecto de la irradiación desde el punto de vista microbiológico y nutricional, y en función del daño potencial a las características organolépticas de las hortalizas (aspecto, color, aroma, dulzura, acidez, amargura, textura y sabor).

La irradiación resultó ser un método eficaz para eliminar el $V$. cholerae en las hortalizas frescas. Las dosis de menos de $0.75 \mathrm{kGy}$ demostraron ser suficientes para eliminar una contaminación inicial de 100000 unidades formadoras de colonias (UFC)/g de V. cholerae. Se concluyó que sería necesaria una dosis de radiación de aproximadamente 0.5 kGy para eliminar una carga de $10000 \mathrm{UFC} / \mathrm{g}$ de $V$. cholerae biotipo El Tor serotipo O1 Inaba en hortalizas frescas, sin alterar las características organolépticas ni la calidad nutricional de las hortalizas, medida según el contenido de vitamina $C$.

\section{Conclusiones}

La irradiación ofrece un gran potencial para mejorar la calidad higiénica de los peces, moluscos y crustáceos y otros mariscos, en particular aquellos que se consumen tradicionalmente crudos. De igual manera, la irradiación puede ayudar a aliviar los problemas de salud pública provocados por la contaminación de hortalizas y frutas frescas con bacterias patógenas, y por la presencia de cisticercos de T. solium en la carne de cerdo.

Se insta a los gobiernos de las Américas a que promuevan la difusión de información sobre la irra- 
diación de alimentos en sus países, y a que sancionen reglamentos nacionales para la aplicación correcta de esta prometedora tecnología. La División Conjunta FAO/OIEA se compromete a colaborar en la preparación de esos reglamentos con base en la Norma General del Codex Alimentarius para Alimentos Irradiados, y en el Reglamento Modelo para Alimentos Irradiados en América Latina y el Caribe elaborado en 1997 con el patrocinio del Grupo Consultivo Internacional sobre Irradiación de los Alimentos. Actualmente, 45 países del mundo, entre ellos Argentina, Brasil, Canadá, Chile, Costa Rica, Cuba, EUA y México, y la Unión Europea, han aprobado la irradiación de uno o varios productos alimenticios o clases de alimentos.

Magda Luz Atrián Salazar. Edición Salud Pública de México.

\section{Llamado de la International Poverty and Health Network a los profesionales de la salud}

La International Poverty and Health Network (IPHN) es una red mundial en la que participan organizaciones e individuos de 46 países, que busca mejorar las condiciones de la salud de la población más pobre en el mundo. Recientemente, Salud Pública de Méxio recibió la invitación, a través de la World Association of Medical Editors (WAME), para difundir un editorial sobre este tema que también será publicado en otras revistas participantes de la WAME. Originalmente escrito por Iona Heath, representante del Intercollegiate Forum on Poverty and Health, y Andy Haines, representando a la IPHN, este editorial fue publicado por el British Medical Jornal en enero de este año. Debido a la importancia del tema, Salud Pública de México decidió publicar una versión en español de este trabajo y ponerlo a disposición de sus lectores de habla hispana:

Siempre y en cualquier lugar, los profesionales de salud enfrentan el reto de entender, desde una posición relativamente cómoda, la naturaleza y alcance de los problemas a los que deben hacer frente los pobres, los marginados y los vulnerables. ${ }^{1}$ A un de manera parcial, el entendimiento crea empatía y una responsabilidad de luchar por una solución.

La Red Internacional de Pobreza y Salud (RIPS) fue creada en diciembre de 1997, a partir de una serie de conferencias organizada por la 0 rganización Mundial de la Salud (O MS). La meta de la Red es "integrar la salud a las políticas y estrategias de erradicación de la pobreza, promoviendo la unión de la comunidad y la acción intersectorial, como un medio para alcanzar resultados efectivos y sostenibles". RIPS se formó en respuesta al creciente sufrimiento humano debido a la pobreza, e invita a otros a unirse a esta causa.

Cerca de 1300 millones de personas viven en pobreza absoluta y abrumadora, con menos de un dólar al día, a pesar del importante crecimiento global de la economía mundial, que se duplicó en los 25 años previos a 1998, hasta alcanzar 24 billones de dólares. ${ }^{2}$ D e los 4400 millones de habitantes de países en desarrollo, casi $60 \%$ carecen de condiciones sanitarias adecuadas, un tercio no tiene acceso a agua potable y $20 \%$ no tiene acceso a atención a la salud; una proporción similar no obtiene suficiente energía y proteína de su dieta.

Las disparidades económicas dentro y entre los países han crecido de tal manera que el ingreso económico de casi 100 países es menor, en términos reales, que hace una década 0 más. ${ }^{3}$ En 1995, el $20 \%$ más rico de la población mundial tenía 82 veces el ingreso económico del $20 \%$ más pobre. Las 225 personas más ricas del mundo poseen en conjunto una riqueza equivalente al ingreso anual de los 2500 millones de personas más pobres del mundo ( $47 \%$ de la población mundial). ${ }^{2} \mathrm{~A}$ I mismo tiempo, el mundo se enfrenta a una creciente escasez de recursos renovables esenciales, como consecuencia de la deforestación, erosión del suelo, la depleción de agua, disminución del caudal pesquero, depleción de la biodiversidad y los retos tales como el cambio climático, los cuales afectan particularmente a las po blaciones pobres y vulnerables.

A pesar del dramático incremento global de la esperanza de vida ocurrido en el siglo pasado, es menester que los profesionales de la salud atiendan las crecientes desigualdades en salud y riqueza. ${ }^{4}$ La drástica caída de la esperanza de vida en Europa 0 riental, particularmente en Rusia, es un claro ejemplo de como la salud puede deteriorarse cuando las sociedades sufren cambios sociales y económicos súbitos, acompañados de creciente pobreza. La brecha entre la esperanza de vida de ciertos países de Europa 0 ccidental y Rusia ha crecido, de aproximadamente tres años para los hombres en 1970, a cerca de 15 años para 1995; las cifras para las mujeres muestran una brecha creciente, de 4 a 10 años para el mismo periodo. ${ }^{5}$ Esta crisis de la salud se manifiesta particularmente en la mortalidad de adultos, por enfermedades crónicas y causas externas, principalmente por violencia. La recesión de Asia 0 riental ha sido profunda y severa, produciendo una fuerte caída del ingreso promedio per cápita en cinco países, particularmente en Indonesia, con efectos similares so bre la po breza y la salud.

Muchos países de Africa tienen deudas externas totales que rebasan el $100 \%$ de su Producto Interno Bruto. A unque han habido avances en la cancelación de la deuda, solamente 22 de los 52 países que requieren de una reducción parcial o total de su deuda podrán reducir sus pagos anuales, gracias a los acuerdos de la Cumbre de Colonia. ${ }^{6}$ Q ueda así mucho por hacer, incluyendo la vigilancia de la forma en que el Banco Mundial (BM) y el Fondo Monetario Internacional (FMI) proponen implementar el programa de reducción de deuda y garantizar que sus recomendaciones de reforma de política económica se enfoquen en la reducción de la pobreza.

Aun entre los países industrializados, generalmente prósperos, tales como España, Finlandia, Suecia, Dinamarca y Estados Unidos de América (EUA), existen varios ejemplos de crecientes desigualdades socioeconómicas en salud durante los últimos 20 años. $^{5}$ En el Reino Unido, el diferencial de mortalidad general entre Clase SocialV (no calificados) y Clase Social I (profesionales) ha aumentado del doble en 1970-1972 a casi el triple en 1991-1993.?

Es particularmente preocupante que las vidas de muchos niños son vejadas por la pobreza y afectadas en su potencial físico y mental. ${ }^{8}$ Aún en EUA, más de 1 en 4 niños menores de 12 años tienen dificultades para obtener sus alimentos necesarios.

La mala salud y la pobreza se refuerzan mutuamente y pueden generar un círculo vicioso de deterioro y sufrimiento. La mala salud contribuye directamente a la menor productividad y, en algunos casos, al desempleo. Sobre todo cuando afecta al principal proveedor familiar de familias pobres, 
frecuentemente tienen implicaciones severas para los niños dependientes económicos y otros miembros de la familia, que pueden ya no ser capaces de mantenerse adecuadamente. Por definición, la gente pobre tiene muy pocos recursos y puede verse forzada a vender sus escasas pertenencias, incluyendo terreno y ganado, 0 a pedir préstamos a altas tasas de interés, para resolver la crisis inmediata precipitada por la enfermedad. Cualquier opción los hace más vulnerables, menos capaces de recuperar su condición previa y en mayor riesgo de descender en la espiral de la pobreza. Por el contrario, los servicios de salud efectivos y accesibles pueden proteger a los pobres de caer en peores condiciones económicas como resultado de la enfermedad, y la atención a la salud basada en la comunidad tiene el potencial de contribuir de manera importante a la construcción del capital social y al fortalecimiento de los mecanismos de sostenimiento propios de la comunidad.

En el siglo XX el desarrollo frecuentemente se ha equiparado con el crecimiento económico; sin embargo, el enlace entre la prosperidad económica y la salud, componente clave del desarrollo humano, no se establece de manera auto mática. Un estudio reciente del BM sobre las causas de la disminución de la mortalidad entre 1960 y 1990, sugirió que la ganancia en el ingreso contribuyó en $20 \%$ a la mortalidad de adultos hombres y mujeres y en la reducción de la tasa de mortalidad de los menores de cinco años. ${ }^{9}$ Los investigadores concluyeron que los factores más importantes fueron el nivel educativo de las mujeres y la generación y utilización de nuevo conocimiento.

La pobreza es una construcción social con muchas dimensiones, que incluye la falta de educación básica, vivienda inadecuada, exclusión social, desempleo, degradación ambiental y bajos ingreso seconómicos. Cada uno de estos factores disminuye la oportunidad, limita la elección y abate la esperanza, además de que cada uno de ellos constituye una amenaza para la salud. Los indicadores económicos se enfocan primordialmente en la pobreza de ingresos, en tanto que los indicadores de salud producen una medida de la naturaleza multidimensional de la pobreza. Por esta razón, la salud debe ser la medida preeminente del éxito o del desarrollo de políticas en este siglo. Son los indicadores de salud, más que los económicos, los que demostrarán la importancia de implementar políticas en diversos sectores, para abatir la tasa de depleción de recursos renovables y, mediante la garantía de los derechos humanos ${ }^{10}$ capitalizar el potencial de aquellos actualmente incapaces de mejorar su calidad de vida.
Los profesionales de la salud luchan por entender detalladamente las experiencias de enfermedad y aflicción de sus pacientes. Siempre que la salud es minada por la pobreza, este entendimiento se convierte, al compartir la frustración e ira de nuestros pacientes, en parte de un proceso de desarrollo de so lidaridad con individuos y comunidades desprotegidos. Una vez expresado el sufrimiento, se vuelve tangible y requiere reparación. Este es uno de los procesos fundamentales de la medicina y la curación y se aplica por igual a la injusticia social. Si nos limitamos a escuchar la historia del que sufre sin luchar junto con él para remediar la situación, desatendemos nuestra tarea.

RIPS es una red mundial de personas y organizaciones de los campos de la salud, negocios, organizaciones no gubernamentales (O N G) y gobiernos, cuyo fin es influir en las políticas para proteger y mejorar la salud de los pobres del mundo, con particular énfasis en los más po bres de todos los países. La Red hace un llamado urgente para lograr el equilibrio entre el desarrollo social y el crecimiento del ingreso per cápita; entre las dimensiones humana y de ingresos de la pobreza; $y$ entre las reformas redistributivas y las de mercado. A nivel de salud, haciendo particular énfasis en las necesidades de los más pobres y más vulnerables, el ideal es lograr un equilibrio entre los abordajes biomédico y social; entre el desarrollo de la salud basado en la comunidad y la respuesta apro piada a las necesidades de los individuos; entre la atención preventiva, promocional y curativa; y entre la salud física y la mental.

En los próximos años, los adeptos a RIPS procurarán reducir la carga de mala salud debida a la pobreza, con la ayuda de los siguientes medios:

- Participación en discusiones estratégicas con instituciones internacionales como el FMI, el BM, O MS y gobiernos nacionales, para asegurar que la salud sea el tema central del desarrollo y que se lleven a cabo evaluaciones del impacto de las políticas sobre la salud.

- Promoción de acciones intersectoriales por la salud, en los ámbitos local, regional y nacional, por medio del trabajo con los sectores de educación negocios, agricultura y transporte, para desarrollar e implementar políticas efectivas.

- $\quad$ Construcción de la base de evidencias sobre inter venciones efectivas para reducir las desigualdades en salud y so bre cómo el mejoramiento de la salud puede reducir la pobreza.

- Facilitación del intercambio del conocimiento entre los profesionales de salud en el N orte y en el Sur, sobre las formas efectivas de trabajo.

- Garantizar que los programas educativos para los profesionales de la salud incluyan información apropiada sobre el impacto de las desigualdades socioeconómicas sobre la salud y sobre qué se puede hacer para reducir tales desigualdades.

- Alentar a los profesionales de la salud a trabajar con las comunidades locales para mejorar la salud de los más pobres.

- Monitoreo de las tendencias de las desigualdades en salud y utilización de datos para influir sobre las políticas.

\section{REFERENCIAS}

1. $N$ athanson V. Humanitarian action:The duty of all doctors. BMJ 1997;315:1389-1390.

2. United $N$ ations Development Programme. Human D evelopment Report 1998. N ueva York: 0 xford University Press, 1998.

3. United Nations Development Programme, Human Development Report 1996, 1997. N ueva York: 0 xford University Press, 1997.

4. MCC ally $M$, Haines $A$, Fein 0 , Addington $W$, Lawrence $R$, C assel $C$. Poverty and III Health: Physicians can and should make a difference. Ann Intern Med, 1998;29:726-733.

5. W hitehead M, Diderichsen F. International evidence on social inequalities in health. En: Drever $F, W$ hitehead $M$, ed. Health inequalities. Londres: 0 ffice of N ational Statistics, 1996.

6. Jubilee $2000 \mathrm{C}$ oalition. Unfinished business. The world's leaders and the millenium debt challenge. Londres: Jubilee 2000 Coalition, 1999.

7. D rever F, Bunting J. Patterns and trends in male mortality. En: D rever F, W hitehead $M$, ed. Health inequalities. Londres: 0 ffice for $\mathrm{N}$ ational Statistics, 1996.

8. Unicef.The State of theW orld's C hildren 1998, N ueva York: 0 xford University Press, 1998.

9. W ang J, Jamison D, Bos E, Preker A, Peabody J. Measuring country performance on health: Selected indicators for 115 countries. W ashington D.C.: The World Bank, Health (N utrition and Population Series), 1999.

10. Bagnoud F-X, Mann JM. Health and human rights. BMJ 1996;312:924-925.

Con este documento, firmado además por representantes de organizaciones regionales e internacionales de Asia, Africa, Oceanía, América y Europa, la International Poverty and Health Network hace un llamado a todos los académicos, investigadores y profesionales de la salud a 
unirse a su iniciativa. Los interesados podrán remitirse a: International Poverty and Health Network (IPHN), Health Link Worldwide, Cityside, 40 Adler Street, London E1 1EE, UK. Tel: 0207539 1570; Fax: 0207 539 1580; E-mail: (Roger Drew) drew.r@healthlink.org.uk. International Poverty and Health Network (IPHN), Community Health Cell, Society for Community Health and Awareness, Research and Action. No. $326,5^{\text {th }}$ Main, $1^{\text {st }}$ Block, Koramangala, Bangalore 560 034, India. E-mail: (Thelma Narayan) sochara@blr.vsnl.net.in at INET.

Carlos Oropeza Abúndez. Editor Ejecutivo, Salud Pública de México. Octavio Gómez Dantés. Editor de Sistemas de Salud, Salud Pública de México.

\section{Ciencia en la frontera: una nueva opción de divulgación científica en el norte de México}

El título de esta nueva revista, Ciencia en la frontera, sugiere que el contenido deberá centrarse en el desarrollo del conocimiento sobre la frontera, en este caso, la frontera norte; sin embargo, debemos ser más específicos. Ciertamente, en general, se habla de las "fronteras de la ciencia" para referirse a un conocimiento actual y moderno pero, sin renunciar a ello, no es ese el concepto implicado en el título de la publicación aquí referida. La intención es, creemos, dar énfasis a la divulgación del conocimiento que se genera, o refiere, a aquellos aspectos de la problemática que encierra el desarrollo de la frontera norte de México y, más específicamente, de la región Paso del Norte, aunque a decir del primer editorial de la revista, pueden llegar a ser aceptados trabajos que, realizados en otras re- giones, compartan o aludan a problemas semejantes que se viven en ésta. Lo anterior quiere decir que eventualmente podrán publicarse las investigaciones realizadas en otros estados y regiones del país con características climáticas similares (zonas áridas) a la referida, o con contenidos relacionados a situaciones de transculturización, migración, población, desarrollo económico sustentado en la industria maquiladora, etcétera, que vengan a ampliar el enfoque o significado de la investigación que se realiza aquí mismo.

Aunado a lo anterior, consideramos que por expresa invitación podrán incluirse artículos de carácter filosófico, social o económico ocasionalmente, siempre y cuando el Consejo Editorial encuentre dicha aportación útil y necesaria.

Ahora bien, Ciencia en la frontera, más allá de servir como un mecanismo de difusión es conveniente considerla como un instrumento de crítica, propuesta y solución de problemas que aquejan el desarrollo sustentable del Norte de México. Por lo tanto, el compromiso es lograr plasmar en un lenguaje claro, accesible y comprensible para los protagonistas del desarrollo socioeconómico regional su contenido, con la finalidad de que seguramente habrá menos excusas para justificar errores o deficiencias en la toma de decisiones que hacen del actual caos una razón de ser. En el primer número es posible advertir dicha intención, y creemos que la responsabilidad inherente debe ser asumida. Es, pues, útil que se diga lo que se sabe acerca del desierto chihuahuense; de cómo debemos preservar la flora y la fauna de los médanos; o de qué hacer con el agua residual, o también de cómo controlar la contaminación atmosférica y lograr la germinación de semillas en condiciones áridas, que son algunas de las respuestas que se inten- tan hacer en esta primera edición de Ciencia en la frontera. El número uno lo complementa un artículo sobre los paradigmas de la ciencia y la investigación.

Ciertamente cualquier parto o nacimiento implica dolor, pero también esperanza. El primer paso está dado y Ciencia en la frontera merece ser una revista que logre, en un futuro no muy lejano, su consolidación. México como nación de casi 100 millones de habitantes posee un número muy escaso de revistas científicas de calidad, y requiere de apoyos para la publicación de los conocimientos científicos que se generan en el país. Es, pues, Ciencia en la frontera, una nueva oportunidad que los mexicanos nos merecemos.

Por otra parte, cabe señalar que el formato de la revista se antoja adecuado, de fácil manejo, indexación y seriación. La calidad de la impresión, siempre mejorable, es ya una muestra del interés de las autoridades universitarias en proporcionar a los investigadores un espacio digno en donde se publiquen sus trabajos, opiniones y críticas. Esta es una revista de la Universidad Autónoma de Ciudad Juárez, y es la primera publicación de carácter científico. Enhorabuena.

Maestro Guillermo Ochoa. Biblioteca Central Universidad Autónoma de Ciudad Juárez, Ciudad Juárez, M éxico.

\section{El Congreso Nacional de Vacunología en vías de convertirse en Congreso Iberoamericano}

El Cuarto Congreso Nacional de Vacunología se llevó a cabo en El Colegio Nacional, ubicado dentro de los límites del Centro Histórico de la ciudad de México, los dos últimos días de noviembre del año anterior. 
La agenda del evento estuvo estructurada por cuatro simposia, dos conferencias magistrales y una sección de temas libres.

Los simposia estuvieron dedicados al uso de citocinas en el desarrollo de vacunas; vacunas producidas en vegetales; el sistema inmunitario de las mucosas y, finalmente, vacunas en medicina veterinaria, de los cuales hacemos los siguientes comentarios:

En el simposio sobre el uso de citocinas para el desarrollo de vacunas se expuso el avance en el conocimiento de las citocinas y su importancia en el desarrollo de vacunas con estas proteínas. Asimismo, se presentaron los adelantos alcanzados en materia de vacunas con citocinas contra el cáncer, la tuberculosis y las infecciones producidas por rotavirus.

En cuanto al simposio sobre vacunas producidas en vegetales podemos decir que en él se describieron las perspectivas y cualidades de las vacunas orales con plantas, así como la producción en plantas de inmunógenos contra enfermedades gastrointestinales y la posible aplicación de vacunas contra enfermedades en animales por vía oral.

En el tercer evento de este tipo, referido al sistema inmunitario de mucosas, se disertó igualmente sobre el desarrollo posnatal de subpoblaciones de células inmunes de la mucosa intestinal; asimismo, se habló de la eficacia de vacunas para infecciones en mucosas, de la aplicación de la protoxina CryAc de $B a-$ cillus thringiensis como adyuvante y acarreador vacunal para la inducción de la respuesta inmune de las mucosas, así como de la producción de vacunas con proteínas autotransportadoras.

Finalmente, el cuarto simposio fue el relativo a vacunas en medicina veterinaria. En él se trató de la eficacia y perspectivas de la vacunación antirrábica en animales silvestres, principalmente en coyotes, por vía oral. También se discutió sobre los marcadores fenotípicos de células de memoria del cerdo, así como de la experiencia en México en el empleo de rugosas de Brucella abortus en la prevención de brucelosis en rumiantes y, finalmente, sobre la producción de biológicos en apoyo a campañas zoosanitarias.

Las dos conferencias magistrales versaron sobre las vacunas antifertilidad, su situación actual y fundamentos metodológicos y teóricos para con su desarrollo, y sobre las vacunas del próximo milenio, así como la inmunización como instrumento de política social de máxima rentabilidad y del avance de la equidad, respectivamente.

En la sección de temas libres se presentaron tópicos de actualidad como: citocinas en el cerebro de ratón infectado con virus de dengue; efecto adyuvante de las citocinas en vacunas de $A D N$; vacunas contra sarampión y rubéola aplicadas por aspiración en aerosol; así también se conferenció sobre la expresión de la pneumolisina y de la proteína PsaA de Streptococcus pneumoniae en una cepa vacunal de Salmonella typhi, y sobre la construcción de una cepa vacunal de Salmonella typhi CVD908htrA que secreta la proteína SSP2 de Plasmodium falciparum y vacunas conjugadas con polisacáridos de $S$. pneumoniae.

En virtud de los éxitos alcanzados hasta este IV Congreso, de periodicidad anual ininterrumpida, la mayoría de los participantes se pronunciaron porque la convocatoria del próximo congreso se haga durante el primer cuatrimestre del año 2000 para poder programar la participación y el envío de resúmenes para la memoria del V Congreso, y porque se considere la posibilidad de convertir dicho evento en un acto latinoamericano, debido, fundamentalmente, a la participación constante de especialistas de los países del subcontinente y para poder ampliar los horizontes de discusión, análisis y de intercambio de experiencias. Por último, la comunidad científica reunida en esta ocasión recomendó estimular la presentación interdisciplinaria de temas de inmunología, tecnología y vacunología, tanto por instituciones del sector público como de la industria privada, así como de los centros académicos y de investigación.

F) López Antuñano. Investigador titular, Instituto Nacional de Salud Pública, México 